\title{
The Role of the CRH Type 1 Receptor in Autonomic Responses to Corticotropin- Releasing Hormone in the Rat
}

\author{
Marjoleen J.M.A. Nijsen, Ph.D., Gerda Croiset, M.D., Ph.D., Ruben Stam, Ph.D., \\ Adrie Bruijnzeel, Michaela Diamant, M.D., Ph.D., David de Wied, M.D., Ph.D., \\ and Victor M. Wiegant, Ph.D.
}

The involvement of the corticotropin-releasing hormone (CRH) type 1 receptor in $\mathrm{CRH}$-induced cardiac responses was studied in freely moving rats. Intracerebroventricular (icv) infusion of $2 \mu \mathrm{g} C R H$ under resting conditions resulted in a significant increase in heart rate (HR), but did not significantly affect the $P Q$ interval of the

electrocardiogram. This effect involves sympathetic nervous system (SNS) activation, since CRH-treatment resulted in a marked increase in plasma norepinephrine (NE) and epinephrine (E), and sympathetic blockade by subcutaneously injected atenolol (1 mg/ $\mathrm{kg})$, a $\beta 1$-selective adrenergic antagonist, completely prevented the $\mathrm{CRH}-$ induced tachycardia. CRH infusion after sympathetic blockade resulted in an elongation of the PQ interval, indicating $\mathrm{CRH}$-induced vagal activation. Gross locomotor activity (GA) was determined to study its possible indirect effects on cardiac activity. Although CRH induced a marked increase in GA, this effect followed the tachycardiac response, indicating that the HR response was not a consequence of increased locomotor activity, but was a direct effect of icv CRH. Treatment with CP-154,526 (icv, 10 or $25 \mu \mathrm{g})$, a selective CRH type 1 receptor antagonist, did not affect baseline HR, plasma NE and $E$, whereas it partially blocked the $C R H$-induced increase in HR, plasma $N E$ and E levels. CP-154,526 treatment had no significant effects on baseline or CRH-induced changes in GA. These results indicate that $C R H$ activates the sympathetic nervous system at least in part via the CRH type 1 receptor. [Neuropsychopharmacology 22: 388-399, 2000] (C) 2000 American College of Neuropsychopharmacology. Published by Elsevier Science Inc.
KEY WORDS: Autonomic Nervous System; Behavior; Hypothalamic-pituitary adrenal-axis; CRH type 1 receptor

From the Rudolf Magnus Institute for Neurosciences, Department of Medical Pharmacology (MJMAN, GC, RS, AB, DdW, VMW), Utrecht University, Utrecht, The Netherlands; Department of Endocrinology and Metabolic Diseases, Leiden University Medical Centre (MD), Leiden, The Netherlands.

Address correspondence to: M.J.M.A. Nijsen, Rudolf Magnus Institute for Neurosciences, Department of Medical Pharmacology, P.O. Box 80040, 3508 TA Utrecht, The Netherlands. Telephone: +31 30 2538845; Fax: +31 30 2539032; E-mail: Nijsen@med.uu.nl

Received June 7, 1999; revised September 13, 1999; accepted September 16, 1999.
Exogenous corticotropin-releasing hormone ( $\mathrm{CRH})$ mimics stress-induced physiological responses in conscious rats, including elevations of heart rate (HR), plasma norepinephrine (NE) and plasma epinephrine (E) (Brown et al. 1982, Fisher et al. 1983, Brown and Fisher 1985, Overton et al. 1990a, Diamant and De Wied 1991, Korte et al. 1993). It is unclear which type of CRH receptor is responsible for these $\mathrm{CRH}$-induced autonomic responses. So far, two types of CRH receptors have been reported in the brain and pituitary: types 1 and 2 . The CRH type 1 receptor has been found predominantly in the pituitary, suggesting a role in the regulation of the hypothalamic-pituitary adrenal (HPA)-axis (Grigoriadis et al. 1996, Dieterich et al. 1997). Both receptor 
types have been localized in subcortical areas of the brain (hypothalamus, amygdala, BNST, hippocampus) that are known to play a role in the regulation of stress responses, including those of the autonomic nervous system (Chalmers et al. 1995, Grigoriadis et al. 1996, Dieterich et al. 1997, Primus et al. 1997). The involvement of the CRH type 1 receptor in behavioral and hormonal stress responses is supported by several functional studies, which show that CRH type 1 but not type 2 receptor knockdown produces anxiolytic-like behavioral effects, and reduces plasma adrenocorticotropic hormone (ACTH) and corticosterone (CS) levels under both basal and stressful conditions in mice (Heinrichs et al. 1997, Smith et al. 1998, Timpl et al. 1998). In addition, Schulz et al. (1996) showed that peripherally administered CP-154,526, a selective CRH type 1 receptor antagonist, reversed the ACTH and startle response induced by centrally administered CRH in rats. To our knowledge, there is no literature available describing the physiological actions of the CRH type 2 receptor. This is caused by the fact that no selective type 2 receptor antagonist is available yet. The above mentioned anatomical studies suggest that both the CRH type 1 an 2 receptor are involved in the regulation of the autonomic nervous system. However, the role of these receptors in autonomic responses has, so far, not been demonstrated.

The aim of the present study was to examine the involvement of the type 1 receptor in CRH-induced autonomic responses. To that end, rats were icv infused with CRH(1-41) alone or in combination with a selective CRH type 1 antagonist, CP-154,526, and studied in their home cages under resting conditions and cardiac (HR and PQ interval), hormonal (E, NE, ACTH) and behavioral (gross locomotor activity (GA)) responses were studied using stressfree techniques. HR and PQ interval of the electrocardiogram were used to evaluate sympathetic nervous system (SNS) and parasympathetic nervous system (PSNS) activity (Croiset et al. 1994, Nijsen et al. 1998a, Nijsen et al. 1998b), whereas the plasma concentration of catecholamines was used as an index of SNS activity (Lake et al. 1976). In addition, behavioral responses were assessed to study its possible effects on cardiac activity and plasma ACTH levels were determined to study the effectiveness of CP-154,526.

\section{METHODS}

\section{Animals and Housing}

Naive male albino Wistar rats (U:WU) weighing 250$300 \mathrm{~g}$ at the beginning of the experiments were used. Rats were housed individually in Macrolon cages $(23 \times$ $17 \times 14 \mathrm{~cm}$ ) containing a layer of woodshavings under conditions of constant ambient temperature $\left(21 \pm 1^{\circ} \mathrm{C}\right)$, constant humidity, and light/dark rhythm (with lights on from 7 A.M. to 7 P.M.). After surgery, the animals were housed individually in Plexiglas cages $(25 \times 25 \times$ $40 \mathrm{~cm}$ ) under presurgical conditions. This housing condition was necessary as the animals were implanted with a telemetric device. The animals were placed on their own receiver and their cages were separated from each other by metal material (Farraday's cage). Food (complete laboratory chow: Hope Farms, Woerden, The Netherlands) and water were accessible ad libitum throughout the experiment.

\section{Experimental Design}

Rats were surgically equipped with a telemetric device to study HR, PQ interval and GA, or with a jugular vein cannula for blood sampling procedures and with an icv cannula for intraventricular infusions. They were allowed to recover from surgery for 10 days in the experimental room. During the recovery period the animals were handled daily for weighing and habituation purposes, and accustomed to icv infusion and blood sampling procedures (twice before the experiment). Infusions and blood sampling were performed stressfree in conscious, resting rats by long-line techniques. All experiments were performed in the home cage during the light phase of the circadian cycle between 9 A.M. and 1 P.M. After the experiment, all rats were killed by an overdose $(0.5 \mathrm{ml})$ of pentobarbital $(160 \mathrm{mg} / \mathrm{ml})$, dissected and macroscopically inspected for infections. In none of the animals were any signs of infection found.

The experiments were approved by the ethical committee for animal experimentation of the Medical Faculty, Utrecht University, The Netherlands.

\section{Experiment 1: Effect of CRH on HR and GA}

Rats were icv infused with 0.5 or $2 \mu \mathrm{g} \mathrm{CRH}$ to determine the dose of CRH that effectively induced cardiac and behavioral changes. Baseline HR and GA of individual, single-housed rats were telemetrically recorded from $t=-30$ to 0 min under resting conditions. Subsequently, rats were icv infused with saline or CRH (0.5 or $2 \mu \mathrm{g}$ ) from $\mathrm{t}=0$ to $6 \mathrm{~min}$ in their home cages. HR and GA were recorded from $\mathrm{t}=0$ to $60 \mathrm{~min}$. As only the dose of $2 \mu \mathrm{g}$ induced a cardiac response, this dose was used in further experiments.

\section{Experiment 2: Effect of Atenolol on CRH-Induced Cardiac and Behavioral Responses}

Rats were pre-treated with atenolol, a $\beta 1$-selective adrenergic antagonist which does not cross the blood brain barrier, to study the relative contribution of sympathetic and vagal outflow to $\mathrm{CRH}$-induced cardiac changes. 
Baseline HR, PQ interval and GA were telemetrically recorded from $t=-50$ to $-20 \mathrm{~min}$. At $\mathrm{t}=-20 \mathrm{~min}$, rats were sc injected with atenolol $(1 \mathrm{mg} / \mathrm{kg}$ in $0.25 \mathrm{ml} \mathrm{sa}-$ line) or saline $(0.25 \mathrm{ml})$. Rats were icv infused with saline or CRH $(2 \mu \mathrm{g})$ from $\mathrm{t}=0$ to $6 \mathrm{~min}$ in their home cages. HR, PQ interval and GA were recorded from $t=$ 0 to $60 \mathrm{~min}$. In a previous experiment (data not published) we found that the cardiac effects (bradycardia and slight increase of PQ interval) of atenolol (1 mg/ $\mathrm{kg}$ ), sc administered to rats in their home cage, occur within $10 \mathrm{~min}$, show a stable dynamic pattern and are present even $60 \mathrm{~min}$ after treatment. Furthermore, it was shown that the cardiac effects of sc injection of saline vanished after $20 \mathrm{~min}$. To avoid interference by the sc injection procedure central infusions were started 20 min later.

\section{Experiment 3: Effect of CP-154,526 on CRH-Induced Cardiac and Behavioral Responses}

Rats were icv infused with CRH, CP-154,526 (a specific antagonist of the CRH type 1 receptor) or a combination of CRH and CP-154,526 to study the role of the type 1 receptor in $\mathrm{CRH}$-induced cardiac and behavioral changes.

Baseline HR, PQ interval and GA were telemetrically recorded from $t=-30$ to $0 \mathrm{~min}$. Subsequently, rats were icv infused with saline, CRH $(2 \mu \mathrm{g})$, or a cocktail of CRH $(2 \mu \mathrm{g})$ and CP-154,526 (10 or $25 \mu \mathrm{g})$ from $\mathrm{t}=0$ to $6 \mathrm{~min}$ and $\mathrm{HR}, \mathrm{PQ}$ interval and GA were recorded from $t=0$ to $60 \mathrm{~min}$.

\section{Experiment 4: Effect of CP-154,526 on CRH-Induced Neuroendocrine Responses}

Rats were icv infused with CRH, CP-154,526 or a combination of CRH and CP-154,526 to study the role of the type 1 receptor in $\mathrm{CRH}$-induced catecholamine (NE, E) and ACTH responses.

Baseline blood samples were drawn at $\mathrm{t}=-10 \mathrm{~min}$. Subsequently, rats were icv infused with saline, $\mathrm{CRH}$ (2 $\mu \mathrm{g})$, or a cocktail of CRH $(2 \mu \mathrm{g})$ and CP-154,526 (10 or $25 \mu \mathrm{g}$ ) from $\mathrm{t}=0$ to $6 \mathrm{~min}$ in their home cages. Additional blood samples were drawn at $\mathrm{t}=1,5,15,35$ and $65 \mathrm{~min}$.

\section{Surgery}

For experiment 1, 2 and 3, rats were equipped with telemetric devices to study HR, PQ interval and GA. For experiment 4 , rats were provided with a cannula in the jugular vein for blood sampling. All rats used received a guide cannula implanted into the lateral brain ventricle for icv infusion. Operations were performed as described in a previous paper (Nijsen et al. 1998b) with some modifications. Two electrodes originate from the top of the telemetric transmitter, one of which was fixed to the dorsal surface of the xiphoid and the other pushed under the $\mathrm{m}$. sternohyoideus and then along the trachea into the anterior mediastinum. After implantation of a telemetric transmitter or jugular vein cannula, all rats received a guide cannula in the lateral ventricle. This cannula consisted of a titanium needle (outer diameter (o.d.) $0.4 \mathrm{~mm}$, inner diameter (i.d.) 0.2 $\mathrm{mm}$ ) and was closed by a tungsten stylet. Postoperatively the animals received $0.1 \mathrm{mg} / \mathrm{kg}$ of the long-acting opiate analgesic buprenorphine hydrochloride (Temge$\mathrm{sic}^{\circledR}$, Reckitt \& Colman, Kingston-upon-Hull, UK; 0.1 $\mathrm{ml}, \mathrm{sc}$ ).

\section{Telemetry}

The telemetry system consisted of small wireless transmitters, model TA11CTA-F40, and receivers, model RLA1020 (both from Data Sciences, Inc., St. Paul, MN, USA). Digital data, ECGs and GA, were transmitted from the receiver to a DataQuest IV data acquisition system (Data Sciences, Inc., St. Paul, MN, USA). 10-sec sampling periods with intervals of $5 \mathrm{~min}$ were used to record ECGs and GA. GA was monitored by digital pulses that indicate the occurrence of an event of movement activity. The rate at which the events were recorded for changes was $64 \mathrm{~Hz}$. These pulses were counted by the DataQuest IV system and totaled over the 10 -sec period. Then the system scaled the raw value to correspond to counts per min. Mean HR was automatically calculated from ECGs by the DataQuest IV data acquisition system. The PQ interval is defined as the interval between the beginning of the $\mathrm{P}$ wave and the beginning of the QRS complex of the ECG. PQ intervals were automatically analyzed from 10-sec ECG recordings and were averaged by a special software program, PhysioStat PS1000 (Data Sciences, Inc., St. Paul, MN, USA).

\section{Intraventricular Infusion and Blood Sampling Procedures}

One hour prior to baseline telemetric measurements, rats were connected to a long $(1.5 \mathrm{~m})$ fused-silica line (i.d. $75 \mu \mathrm{m}$, o.d. $150 \mu \mathrm{m}$; Composite Metal Services LTD, Hallow, United Kingdom), guided by a polyethylene tube (i.d. $0.28 \mathrm{~mm}$, o.d. $0.61 \mathrm{~mm}$; Portex, Hythe, Kent, United Kingdom), for stressfree icv infusion. The long-line was attached to a syringe in a microinfusion pump (Harvard Apparatus, Inc., Massachusetts, USA). Central infusions were performed at $3 \mu \mathrm{l} / 6 \mathrm{~min}$. In addition, one hour prior to withdrawal of baseline blood samples, rats were connected with a long $(1 \mathrm{~m})$ polyethylene tube (i.d. $0.76 \mathrm{~mm}$, o.d. $1.22 \mathrm{~mm}$ ) which was attached to a syringe, for stressfree blood sampling according to Steffens (1969). Samples $(350-400 \mu l)$ were 
collected in small cups containing an ice-cooled solution in saline of heparin $(10 \mu \mathrm{l} ; 500 \mathrm{IU} / \mathrm{ml})$ and EDTA $(10 \mu \mathrm{l} ; 44 \mathrm{mg} / \mathrm{ml})$, mixed, and centrifuged (10 $\mathrm{min}, 4000$ $\left.\mathrm{rpm}, 4^{\circ} \mathrm{C}\right)$. Plasma was separated and aliquots were stored at $-20^{\circ} \mathrm{C}$ (for ACTH) or $-80^{\circ} \mathrm{C}$ (for catecholamines). The volume of sampled blood was substituted by saline, in order to avoid volume changes. During icv infusion or basal blood withdrawal all rats were asleep. No HR, GA or hormone responses were seen in rats infused with saline, indicating that our long-line techniques are under minimal stress indeed.

\section{ACTH Determination}

The concentration of ACTH in plasma was determined by radioimmunoassay. Assays were performed in duplicate according to the procedure described by Van Oers and Tilders (1991), using a specific rabbit antiserum directed to the mid-portion of ACTH (code Ft 8514) kindly donated by Dr G.B. Makara (Budapest, Hungary). Synthetic human $\mathrm{ACTH}_{1-39}$ (Peninsula Laboratories, Belmont, CA, USA) was used as standard, and ${ }^{125}$ I-labelled $\mathrm{ACTH}_{1-39}$ (Iodogen ${ }^{\circledR}$ method) as tracer. Sample dilution curves paralleled the standard curve. The sensitivity of the assay, calculated at $\mathrm{B} / \mathrm{B} 0=0.9$, was $10 \mathrm{pg} / \mathrm{ml}$ plasma ( $0.5 \mathrm{pg} /$ tube). Intra- and interassay variations were $5 \%$ and $8 \%$ respectively.

\section{Catecholamine Determination}

Catecholamine levels were determined as described in a previous paper (Nijsen et al. 1998b).

\section{Drug Treatment}

Corticotropin-releasing hormone (hCRH(1-41) was obtained from Peninsula, Belmont, CA, USA; the selective $\beta 1$-selective adrenergic receptor antagonist, atenolol from Sigma, Zwijndrecht, The Netherlands and the selective CRH type 1 receptor antagonist, CP-154,526 was synthesized and kindly donated by Dr. J. den Hartog, Solvay Pharmaceuticals, Weesp, The Netherlands. All drugs were dissolved in saline prior to use.

\section{Statistics}

GA (counts/min), HR (beats/min) and PQ interval (msec) are presented as mean changes ( \pm SEM) in comparison to baseline. NE, E and ACTH concentrations are presented as mean $\mathrm{pg} / \mathrm{ml}( \pm \mathrm{SEM})$. Baseline levels of the treatment groups were compared by a one-way Analysis of Variance (ANOVA) and post-hoc Student
Newman-Keuls test. All data were analyzed by a twofactor Multivariate Analysis of Variance (MANOVA) with repeated measures. In experiments 1,3 and 4 one between-subjects factor (treatment) and one repeated measures within-subjects factor (time) were used. In experiment 2, two between-subjects factors (CRH treatment and atenolol treatment) and one repeated measures within-subjects factor (time) were used. In experiment 1 , the treatment factor had three levels (saline, $\mathrm{CRH}(0.5 \mu \mathrm{g})$ and $\mathrm{CRH}(2 \mu \mathrm{g}))$ and the time factor had twelve levels. In experiment 2 , the treatment factors had two levels (saline vs. CRH; saline vs. atenolol) and the time factor had twelve levels. In experiments 3 and 4, the treatment factor had six levels (saline, CP-154,526 $(10 \mu \mathrm{g}), \mathrm{CP}-154,526(25 \mu \mathrm{g}), \mathrm{CRH}, \mathrm{CRH} / \mathrm{CP}-154,526$ (10 $\mu \mathrm{g})$ and CRH/CP-154,526 (25 $\mu \mathrm{g}))$. The time factor had twelve (telemetry data) or five (hormonal data) levels. Via contrasts it was statistically analyzed whether individual groups (saline vs. CP-154,526 $(10 \mu \mathrm{g})$, saline vs. $\mathrm{CP}-154,526(25 \mu \mathrm{g})$, saline vs. CRH, CRH vs. CRH/CP$154,526(10 \mu \mathrm{g}), \mathrm{CRH}$ vs. CRH/CP-154,526 (25 $\mu \mathrm{g})$,

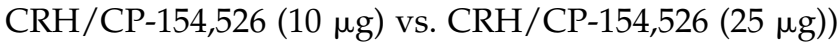
were significantly different. A value of $p<.05$ was considered significant. Due to insufficient quality of the telemetric signal, the following data had to be excluded from further analysis: the PQ interval of one atenolol/ $\mathrm{CRH}$ and two atenolol/saline rats (Figure 1C); the PQ interval of two CP-154,526 (25 $\mu \mathrm{g})$, one CRH, one CRH/ $\mathrm{CP}-154,526(10 \mu \mathrm{g})$ and one CRH/CP-154,526 (25 $\mu \mathrm{g})$ rat (Figure 2C).

\section{RESULTS}

\section{Experiment 1: Effect of CRH on HR and GA}

HR and GA. Baseline HR, determined prior to icv infusion, was $357 \pm 7$ beats/min for the saline (SAL) group, $343 \pm 9$ beats $/ \mathrm{min}$ for the $0.5 \mu \mathrm{g}$ CRH group and $352 \pm 7$ beats $/ \mathrm{min}$ for the $2 \mu \mathrm{g}$ CRH group. Baseline GA was $0.5 \pm 0.2$ counts $/ \mathrm{min}$ for the SAL group, $0.3 \pm 0.1$ counts $/ \mathrm{min}$ for the $0.5 \mu \mathrm{g}$ CRH group and $0.3 \pm$ 0.1 counts/min for the $2 \mu \mathrm{g}$ CRH group. Baseline HR and GA were not significantly different between the three groups of rats.

$\mathrm{CRH}$-induced responses (HR and GA) are shown in Figure 1. For the HR response, MANOVA on all groups showed significant treatment $(\mathrm{F}(2,21)=17.4, p<.001)$, time $(\mathrm{F}(11,231)=5.8, p<.001)$ and treatment by time interaction effects $(\mathrm{F}(22,231)=7.7, p<.001)$. For the GA response, MANOVA on all groups showed significant treatment $(\mathrm{F}(2,21)=43.4, p<.001)$, time $(\mathrm{F}(11,231)=$ $4.4, p<.001)$, and treatment by time interaction effects $(\mathrm{F}(22,231)=3.7, p<.001)$. Only the high dose of CRH $(2$ $\mu \mathrm{g}$ ) enhanced HR (treatment effect, $p<.001$; treatment by time interaction, $p<.001$ ) and GA (treatment effect, 

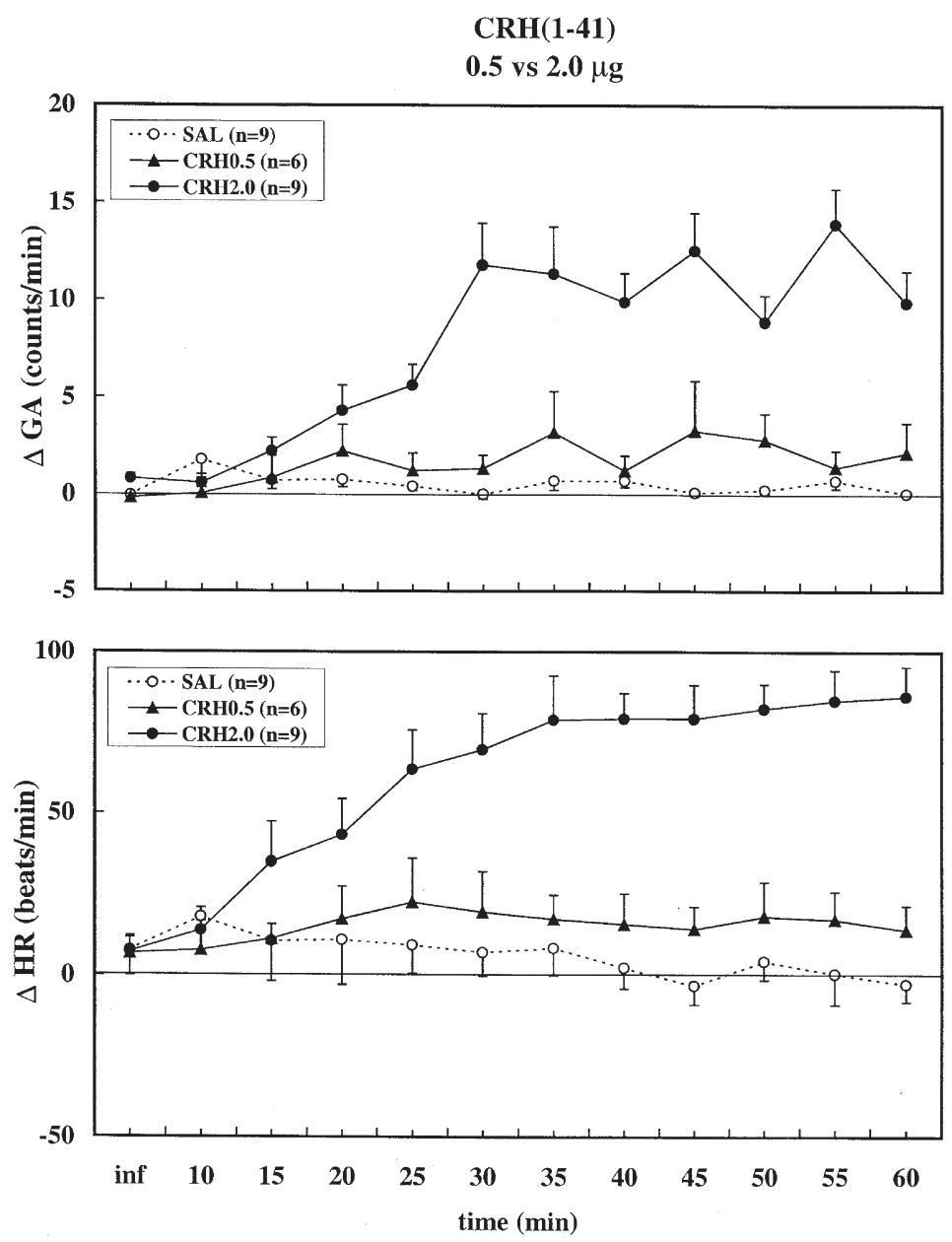

Figure 1. Changes in heart rate (HR) (lower panel) and gross locomotor activity (GA) (upper panel) in rats treated with saline (SAL), $0.5 \mu \mathrm{g}$ CRH(1-41) (CRH0.5) or $2 \mu \mathrm{g}$ CRH(1-41) (CRH2.0) in their home cages. Infusions of saline and $\mathrm{CRH}$ were given icv from $t=0$ to $6 \mathrm{~min}$ (inf). Data reflect delta values $(\Delta)$ in comparison to baseline and are presented as mean \pm S.E.M. $p<.001$; treatment by time interaction, $p<.001)$ as compared to saline treatment. Figure 1 shows that the increase in HR developed after approximately $10 \mathrm{~min}$, whereas the increase in GA mainly developed after 15 min. The dose of $2 \mu \mathrm{g}$ was used for further experiments.

\section{Experiment 2: Effect of Atenolol on CRH-Induced Cardiac and Behavioral Responses}

HR. Baseline HR, determined prior to sc pre-treatments, was $339 \pm 4$ beats/min in the SAL/SAL group, $345 \pm 4$ beats $/ \mathrm{min}$ in the SAL/CRH group, $331 \pm 4$ beats/min in the AT/SAL group and $332 \pm 6$ beats/ min in the AT/CRH group. Baseline HR was not significantly different between the four groups of rats.

Figure 2A depicts the CRH-induced HR response in saline and atenolol pre-treated rats. CRH treatment significantly enhanced $\mathrm{HR}$ as compared to saline treatment (CRH treatment effect: $\mathrm{F}(1,28)=31.6, p<.001)$, and Figure 2A shows that this effect already started during icv infusion. Pre-treatment with atenolol resulted in a reduction of the $\mathrm{CRH}$-induced HR response (interaction of atenolol by CRH treatment: $\mathrm{F}(1,28)=6.0$, $p<.05$; interaction of atenolol treatment by CRH treatment by time: $\mathrm{F}(11,308)=3.8, p<.001)$. In atenolol pretreated rats, the HR response was significantly different from that in saline pre-treated rats (atenolol treatment effect: $\mathrm{F}(1,28)=11.3, p<.001$; atenolol treatment by time effect: $\mathrm{F}(11,308)=2.6, p<.005)$.

PQ Interval. Baseline values for PQ interval, determined prior to sc pre-treatments, were $50.4 \pm 1.5 \mathrm{msec}$ in the SAL/SAL group, $54.2 \pm 2.3 \mathrm{msec}$ in the SAL/ CRH group, $52.2 \pm 1.4$ in the AT/SAL group and $54.7 \pm$ $1.1 \mathrm{msec}$ in the AT/CRH group. Baseline values were not significantly different between the 4 groups of rats.

Figure 2B depicts the CRH-induced changes in $P Q$ interval in saline and atenolol pre-treated rats. MANOVA on all groups revealed a significant time effect $(\mathrm{F}(11,275)=8.9, p<.001)$. In time, $\mathrm{CRH}$ treatment significantly prolonged the PQ interval as compared to saline treatment (CRH treatment by time effect: $\mathrm{F}(11,275)=$ $7.6, p<.001)$. In atenolol pre-treated rats, the PQ interval was significantly higher as compared to saline pretreated rats (atenolol treatment effect: $\mathrm{F}(1,25)=5.3, p<$ 

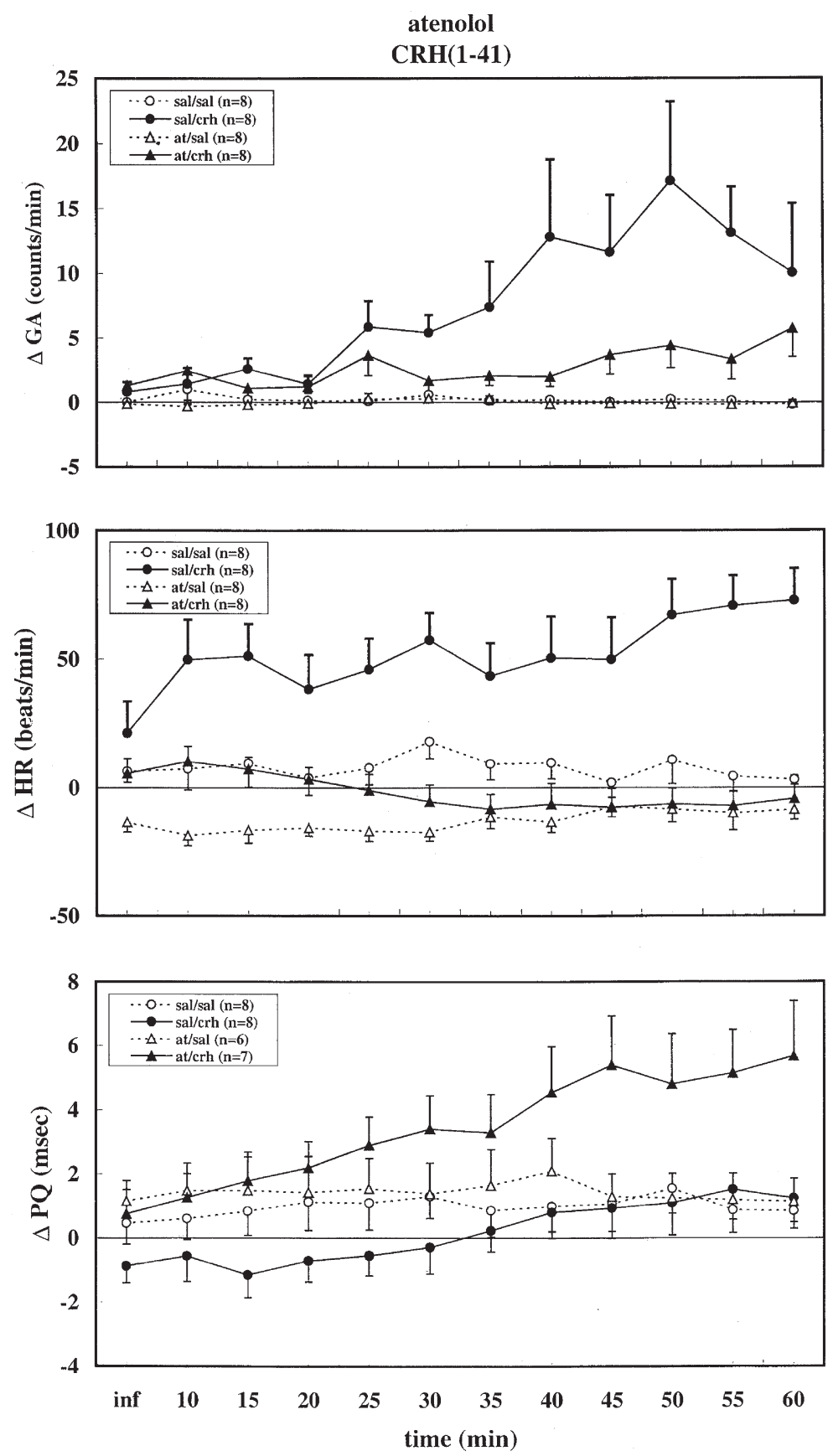

Figure 2. Changes in heart rate (HR) (middle panel), PQ interval (lower panel) and gross locomotor activity (GA) (upper panel) in rats treated with saline/saline (sal/sal), saline/CRH(1-41) (sal/crh), atenolol/saline (at/sal) and atenolol/ $\mathrm{CRH}(1-41)(\mathrm{at} / \mathrm{crh})$ in their home cages. Injections of saline and atenolol $(1 \mathrm{mg} / \mathrm{kg})$ were given sc at $\mathrm{t}=-20 \mathrm{~min}$; infusions of saline and CRH $(2 \mu \mathrm{g})$ were given icv from $t=0$ to $6 \mathrm{~min}$ (inf). Data reflect delta values $(\Delta)$ in comparison to baseline and are presented as mean \pm S.E.M.
.05). MANOVA showed a tendency towards an increase of the CRH-induced PQ response in atenol treated rats (interaction of atenolol by CRH treatment: $\mathrm{F}(1,25)=3.0$, $p=.09)$.

GA. Baseline GA, determined prior to sc pre-treatments, was $0.2 \pm 0.1$ counts/min in the SAL/SAL group, $0 \pm 0$ counts $/ \mathrm{min}$ in the SAL/CRH group, $0.3 \pm$ 0.2 counts/min in the AT/SAL group and $0.5 \pm 0.3$ counts/min for the AT/CRH group. Baseline values were not significantly different between the 4 groups of rats.
Figure $2 \mathrm{C}$ depicts the $\mathrm{CRH}$-induced GA response in saline and atenolol pre-treated rats. MANOVA on all groups revealed a significant time effect $(\mathrm{F}(11,308)=4.9, p<.001)$. $\mathrm{CRH}$ treatment enhanced GA (CRH treatment effect: $\mathrm{F}(1,28)=21.0, p<.001)$. The pattern of the GA response in $\mathrm{CRH}$ treated rats was significantly different from that in saline treated rats (CRH treatment by time effect: $\mathrm{F}(11,308)=$ 5.4, $p<.001$ ) and Figure $2 \mathrm{C}$ shows that this effect mainly developed after $\mathrm{t}=20 \mathrm{~min}$. Pre-treatment with atenolol resulted in a reduction of the CRH-induced GA response (interaction of atenolol treatment by CRH treatment by 
time: $\mathrm{F}(11,308)=2.0, p<.05)$. Furthermore, the time course of the GA response in atenolol pre-treated rats was significantly different from that in saline pre-treated rats (atenolol treatment by time effect: $\mathrm{F}(11,308)=1.8, p<.05)$.

\section{Experiment 3: Effect of CP-154,526 on CRH-Induced Cardiac and Behavioral Responses}

HR. Baseline HR, determined prior to icv infusion, was $349 \pm 2$ beats $/ \mathrm{min}$ for the saline group, $352 \pm 8$ beats $/ \mathrm{min}$ for the CP-154,526 (10 $\mu \mathrm{g})$ group, $358 \pm 7$ beats $/ \mathrm{min}$ for the CP-154,526 (25 $\mu \mathrm{g})$ group, $363 \pm 3$ beats $/ \mathrm{min}$ for the CRH group, $351 \pm 9$ beats/min for the CRH/CP-154,526 $(10 \mu \mathrm{g})$ group and $352 \pm 5$ beats/min for the CRH/CP$154,526(25 \mu \mathrm{g})$ group. ANOVA did not reveal significant differences in baseline HR between the 6 treatment groups.

Figure 3A depicts the changes in $\mathrm{HR}$ to icv infusion of saline, CP-154,526, CRH and CRH/CP-154,526. MANOVA on all groups showed significant treatment $(\mathrm{F}(5,36=8.7, p<.001)$, time $(\mathrm{F}(11,396)=6.2, p<.001)$, and treatment by time interaction effects $(\mathrm{F}(55,396)=$ $2.2, p<.05)$. CRH treatment enhanced HR for at least 60 min (treatment effect, $p<.001$; treatment by time interaction, $p<.005$ ) and Figure 3A shows that this effect started already during icv infusion. The $\mathrm{CRH}$-induced increase in HR was significantly reduced by both $10 \mu \mathrm{g}$ (treatment effect, $p<.05$ ) and $25 \mu \mathrm{g}$ (treatment effect, $p<$ .05) CP-154,526 to a similar extent. Treatment with CP154,526 alone in a dose of 10 and $25 \mu \mathrm{g}$ had no significant treatment or time effects on HR in comparison to saline treatment.

PQ Interval. Baseline PQ interval, determined prior to icv infusion, was $52.7 \pm 1.0 \mathrm{msec}$ for the saline group, $53.9 \pm 1.2 \mathrm{msec}$ for the CP-154,526 (10 $\mu \mathrm{g})$ group, $51.8 \pm$ $1.1 \mathrm{msec}$ for the CP-154,526 (25 $\mu \mathrm{g})$ group, $50.5 \pm 1.5$ msec for the CRH group, $54.5 \pm 0.6 \mathrm{msec}$ for the CRH/ $\mathrm{CP}-154,526(10 \mu \mathrm{g})$ group and $52.9 \pm 0.9 \mathrm{msec}$ for the $\mathrm{CRH} / \mathrm{CP}-154,526(25 \mu \mathrm{g})$ group. ANOVA did not reveal significant differences in baseline PQ interval between the 6 treatment groups.

Figure $3 \mathrm{~B}$ depicts the changes in $\mathrm{PQ}$ interval to icv infusion of saline, CP-154,526, CRH and CRH/CP154,526 . MANOVA on all groups showed no significant time, treatment, or interaction of treatment by time effects.

GA. Baseline GA, determined prior to icv infusion, was $0.3 \pm 0.1$ counts $/ \mathrm{min}$ for the saline group, $0.4 \pm 0.2$ counts/ $\mathrm{min}$ for the CP-154,526 $(10 \mu \mathrm{g})$ group, $0.7 \pm 0.3$ counts $/ \mathrm{min}$ for the CP-154,526 (25 $\mu \mathrm{g})$ group, $0.1 \pm 0.1$ counts $/ \mathrm{min}$ for the CRH group, $0.6 \pm 0.3$ counts $/ \mathrm{min}$ for the $\mathrm{CRH} / \mathrm{CP}-$ $154,526(10 \mu \mathrm{g})$ group and $0.4 \pm 0.2$ counts $/ \mathrm{min}$ for the $\mathrm{CRH} / \mathrm{CP}-154,526(25 \mu \mathrm{g})$ group. ANOVA did not reveal significant differences in baseline GA between the 6 treatment groups.
Figure $3 \mathrm{C}$ depicts the changes in $\mathrm{HR}$ to icv infusion of saline, CP-154,526, CRH and CRH/CP-154,526. MANOVA on all groups showed significant treatment $(\mathrm{F}(5,36)=6.8, p<.001)$, time $(\mathrm{F}(11,396)=6.7, p<.001)$, and treatment by time interaction effects $(\mathrm{F}(55,396)=$ $2.1, p<.001$ ). CRH treatment enhanced GA (treatment effect, $p<.001$; treatment by time interaction, $p<.001$ ). Figure $3 \mathrm{C}$ shows that this effect mainly developed after $\mathrm{t}=30 \mathrm{~min}$. The CRH-induced increase in GA was not significantly reduced by 10 or $25 \mu \mathrm{g}$ CP-154,526 treatment. Both the dose of $10 \mu \mathrm{g}$ CP-154,526 (treatment ef-

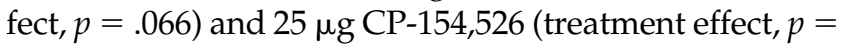
.069 ; treatment by time interaction, $p=.088$ ) showed a trend towards a reduction of the GA response as compared to saline treatment. Treatment with CP-154,526 alone in a dose of 10 and $25 \mu \mathrm{g}$ had no significant treatment or time effects on GA in comparison to saline treatment.

\section{Experiment 4: Effect of CP-154,526 on CRH-Induced Neuroendocrine Responses}

NE. Baseline concentrations of NE in plasma, determined prior to icv infusion, were $82 \pm 3 \mathrm{pg} / \mathrm{ml}$ for the saline group, $80 \pm 2 \mathrm{pg} / \mathrm{ml}$ for the CP-154,526 (10 $\mu \mathrm{g})$ group, $88 \pm 2 \mathrm{pg} / \mathrm{ml}$ for the CP-154,526 (25 $\mu \mathrm{g})$ group, $87 \pm 3 \mathrm{pg} / \mathrm{ml}$ for the CRH group, $87 \pm 4 \mathrm{pg} / \mathrm{ml}$ for the $\mathrm{CRH} / \mathrm{CP}-154,526(10 \mu \mathrm{g})$ group and $89 \pm 4 \mathrm{pg} / \mathrm{ml}$ for the CRH/CP-154,526 (25 $\mu \mathrm{g})$ group. ANOVA did not reveal significant differences in baseline NE between the treatment groups.

Figure 4A depicts the changes in plasma NE concentrations to icv infusion of saline, CP-154,526, CRH and CRH/CP-154,526. MANOVA on all groups showed significant treatment $(\mathrm{F}(5,39)=65.9, p<.001)$, time $(\mathrm{F}(4,156)=289, p<.001)$, and treatment by time interaction effects $(\mathrm{F}(20,156)=52.5, p<.001)$. CRH treatment enhanced plasma NE for at least 65 min (treatment effect, $p<.001$; treatment by time interaction, $p<$ $.001)$. This increase was significantly reduced by $10 \mu \mathrm{g}$ CP-154,526 (treatment effect, $p<.05$; treatment by time interaction, $p<.05$ ) and $25 \mu \mathrm{g}$ CP-154,526 (treatment effect, $p<.05$; treatment by time interaction, $p<.01$ ). Treatment with CP-154,526 alone in a dose of 10 and 25 $\mu \mathrm{g}$ had no significant treatment or time effects in comparison to saline treatment.

E. Baseline concentrations of $\mathrm{E}$ in plasma, determined prior to icv infusion, were $60 \pm 3 \mathrm{pg} / \mathrm{ml}$ for the saline group, $55 \pm 2 \mathrm{pg} / \mathrm{ml}$ for the CP-154,526 (10 $\mu \mathrm{g})$ group, $62 \pm 2 \mathrm{pg} / \mathrm{ml}$ for the CP-154,526 (25 $\mu \mathrm{g})$ group, $63 \pm 4$ $\mathrm{pg} / \mathrm{ml}$ for the CRH group, $69 \pm 12 \mathrm{pg} / \mathrm{ml}$ for the CRH/ CP-154,526 $(10 \mu \mathrm{g})$ group and $61 \pm 4 \mathrm{pg} / \mathrm{ml}$ for the CRH/CP-154,526 (25 $\mu \mathrm{g})$ group. ANOVA did not reveal significant differences in baseline $E$ between the treatment groups. 

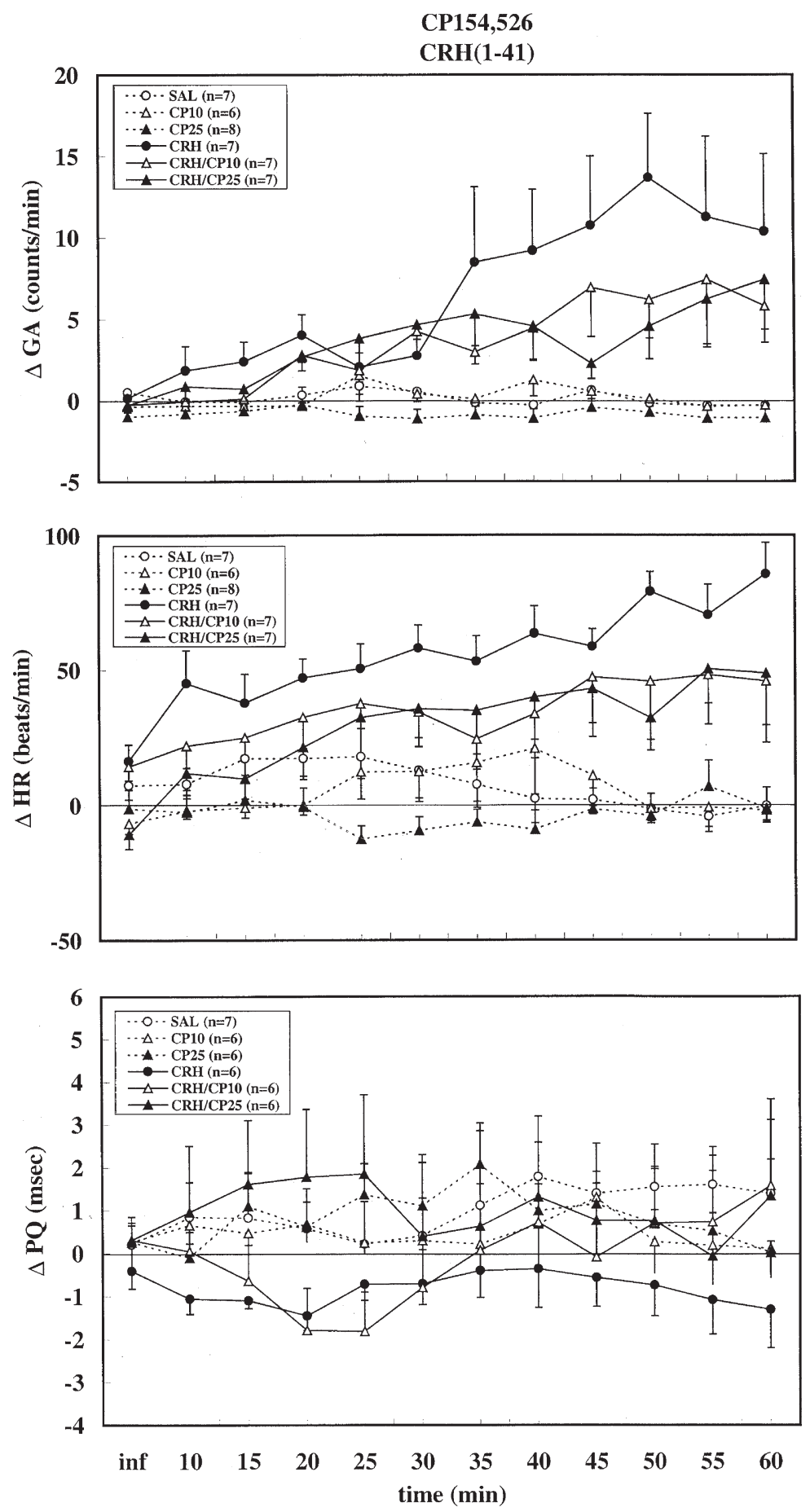

Figure 3. Changes in heart rate (HR) (middle panel), PQ interval (lower panel) and gross activity (GA) (upper panel) in rats treated with saline (SAL), $2 \mu \mathrm{g}$ CRH(1-41) (CRH), $10 \mu \mathrm{g} \mathrm{CP-154,526}$ (CP10), $25 \mu \mathrm{g}$ CP-154,526 (CP25), cocktail of $\mathrm{CRH}(1-41)$ and $10 \mu \mathrm{g}$ CP-154,526 (CRH/CP10) or cocktail of CRH(1-41) and $25 \mu \mathrm{g}$ CP-154,526 $(\mathrm{CRH} / \mathrm{CP} 25)$ in their home cages. Infusions were given icv from $\mathrm{t}=0$ to $6 \mathrm{~min}$ (inf). Data reflect delta values $(\Delta)$ in comparison to baseline and are presented as mean \pm S.E.M.
Figure 4B depicts the changes in plasma E concentrations to icv infusion of saline, CP-154,526, CRH and CRH/CP-154,526. MANOVA on all groups showed significant treatment $(\mathrm{F}(5,39)=41.7, p<.001)$, time $(\mathrm{F}(4,156)=139, p<.001)$, and treatment by time interaction effects $(\mathrm{F}(20,156)=26.4, p<.001)$. CRH treatment enhanced plasma $\mathrm{E}$ for at least $65 \mathrm{~min}$ (treatment effect, $p<.001$; treatment by time interaction, $p<.001$ ). This increase was significantly reduced by both $10 \mu \mathrm{g}$
CP-154,526 (treatment effect, $p<.05$; treatment by time interaction, $p<.005$ ) and $25 \mu \mathrm{g}$ CP-154,526 (treatment effect, $p<.01$; treatment by time interaction, $p<.01$ ). Treatment with CP-154,526 alone in a dose of 10 or 25 $\mu \mathrm{g}$ had no significant treatment or time effect in comparison to saline treatment.

ACTH. Baseline concentrations of ACTH in plasma, determined prior to icv infusion, were $58 \pm 5 \mathrm{pg} / \mathrm{ml}$ for 

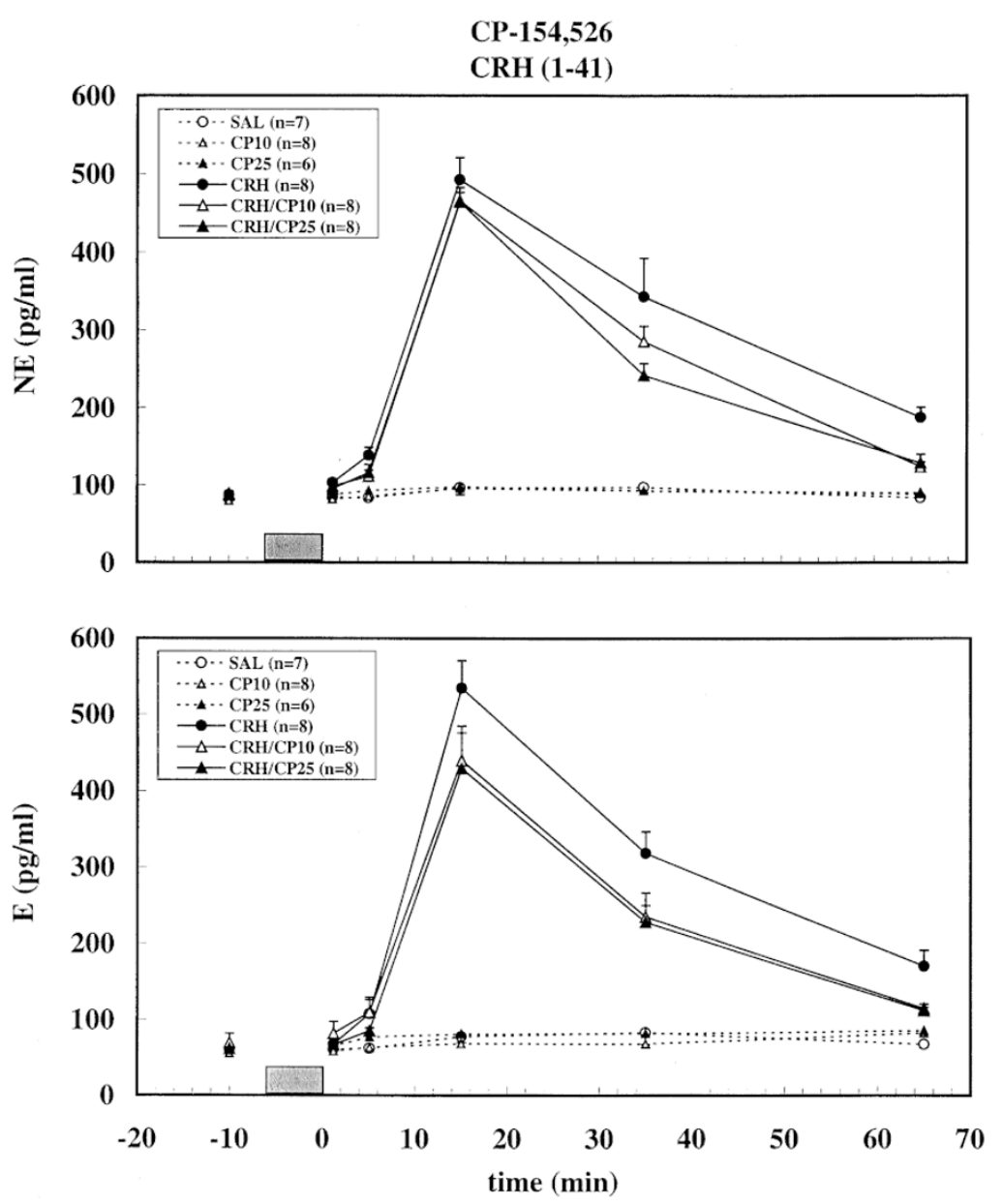

Figure 4. Norepinephrine (NE) (upper panel) and epinephrine (E) (lower panel) levels in rats treated with saline (SAL), $2 \mu \mathrm{g} \mathrm{CRH}(1-41)$ (CRH), $10 \mu \mathrm{g}$ CP-154,526 (CP10), $25 \mu \mathrm{g} \mathrm{CP-}$ 154,526 (CP25), cocktail of CRH(1-41) and $10 \mu \mathrm{g}$ CP-154,526 (CRH/CP10) or cocktail of CRH(1$41)$ and $25 \mu \mathrm{g}$ CP-154,526 (CRH/CP25) in their home cages. Infusions were given icv from $t=$ -6 to $0 \mathrm{~min}$ (bar). Data are presented as mean \pm S.E.M. the saline group, $60 \pm 12 \mathrm{pg} / \mathrm{ml}$ for the CP-154,526 (10 $\mu \mathrm{g})$ group, $44 \pm 3 \mathrm{pg} / \mathrm{ml}$ for the CP-154,526 (25 $\mu \mathrm{g})$ group, $70 \pm 7 \mathrm{pg} / \mathrm{ml}$ for the CRH group, $86 \pm 7 \mathrm{pg} / \mathrm{ml}$ for the CRH/CP-154,526 (10 $\mu \mathrm{g})$ group and $61 \pm 11 \mathrm{pg} /$ $\mathrm{ml}$ for the CRH/CP-154,526 (25 $\mu \mathrm{g})$ group. ANOVA did not reveal significant differences in baseline ACTH between the treatment groups.

Figure 5 depicts the changes in plasma ACTH concentrations to icv infusion of saline, CP-154,526, CRH and $\mathrm{CRH} / \mathrm{CP}-154,526$. After icv infusion, MANOVA on all groups showed significant treatment $(\mathrm{F}(5,39)=24.2$, $p<.001)$, time $(\mathrm{F}(4,156)=22.3, p<.001)$, and treatment by time interaction effects $(\mathrm{F}(20,156)=6.8, p<.001)$. $\mathrm{CRH}$ treatment enhanced ACTH for at least $65 \mathrm{~min}$ (treatment effect, $p<.001$; treatment by time interaction, $p<.001)$. The $\mathrm{CRH}$-induced increase in ACTH was significantly reduced by $25 \mu \mathrm{g}$ CP-154,526 (treatment effect, $p<.01$; treatment by time interaction, $p<.005)$. There was a trend that $10 \mu \mathrm{g} \mathrm{CP}-154,526$ reduced the CRH-induced ACTH response $(p=.08)$. Treatment with CRH/CP-154,526 (10 $\mu \mathrm{g})$ resulted in a significantly higher ACTH response than treatment with CRH/CP-154,526 (25 $\mu \mathrm{g})$ (treatment by time interaction, $p<.05)$. Treatment with CP-154,526 alone in a dose of 10 and $25 \mu \mathrm{g}$ had no significant treatment or time effects on ACTH in comparison to saline treatment.

\section{DISCUSSION}

In the present study, it was demonstrated that icv infusion of CRH in resting rats induced an increase in HR, but no significant change in PQ interval. These cardiac effects involve SNS activation, since icv infusion of CRH resulted in a marked increase in plasma NE and $\mathrm{E}$ and sympathetic blockade by atenolol resulted in a complete blockade of the CRH-induced tachycardia. CRH infusion after sympathetic blockade resulted in an elongation of the $\mathrm{PQ}$ interval, indicating that $\mathrm{CRH}$ activated the PSNS. Treatment with CP-154,526, a selective $\mathrm{CRH}$ type 1 receptor antagonist, resulted in a significant partial inhibition of the CRH-induced increase in HR, plasma NE and E levels, but had no significant effect on the PQ interval. Taken together, these results indicate 


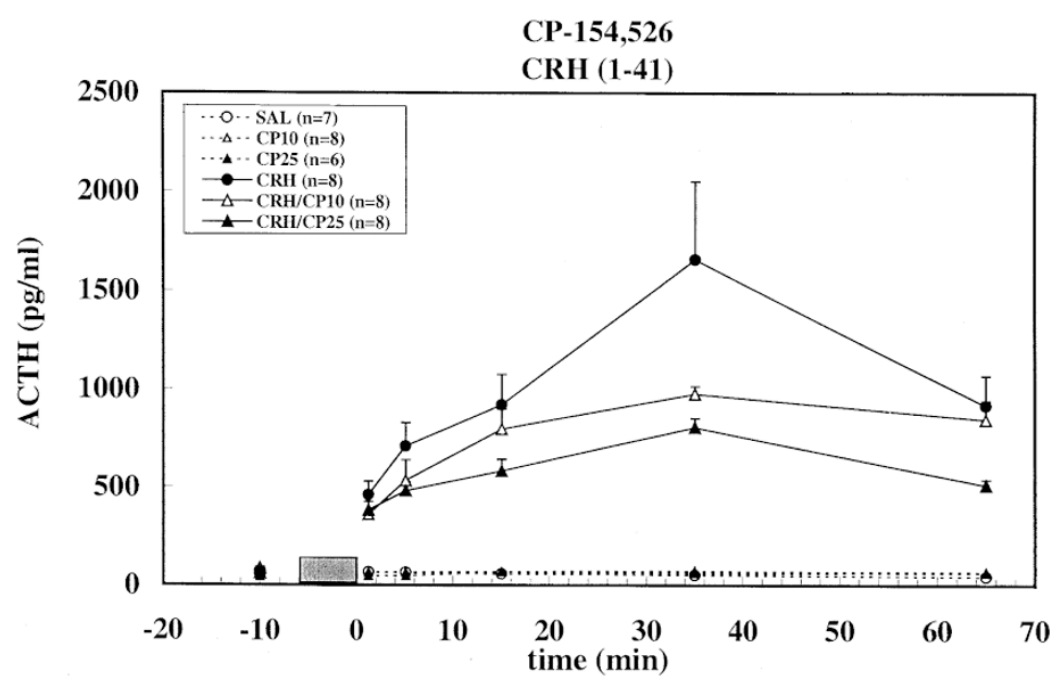

Figure 5. Adrenocorticotropin-releasing hormone $(\mathrm{ACTH})$ levels in rats treated with saline (SAL), $2 \mu \mathrm{g} \mathrm{CRH(1-41)} \mathrm{(CRH),} 10 \mu \mathrm{g}$ CP-154,526 (CP10), $25 \mu \mathrm{g}$ CP-154,526 (CP25), cocktail of $\mathrm{CRH}(1-41)$ and $10 \mu \mathrm{g}$ CP-154,526 (CRH/CP10) or cocktail of CRH(1-41) and 25 $\mu \mathrm{g}$ CP-154,526 (CRH/CP25) in their home cages. Infusions were given icv from $t=-6$ to $0 \mathrm{~min}$ (bar). Data are presented as mean \pm S.E.M. that the type 1 receptor plays a role in the activation of the SNS that is induced by icv administration of CRH.

The results of the present study show that a relatively low dose of CRH $(0.5 \mu \mathrm{g})$ in rats during rest exerted no profound effect on HR, whereas administration of a higher dose $(2 \mu \mathrm{g})$ resulted in a marked increase in HR. The dose of $2 \mu \mathrm{g}$ was used for further experiments, which revealed that NE and E concentrations were also enhanced by CRH treatment. The elevation in HR, plasma NE and E levels suggests that $\mathrm{CRH}$ activated the SNS (Lake et al. 1976). Indeed, sc injection of atenolol, a selective adrenergic $\beta 1$-antagonist, blocked the CRH-induced tachycardia, indicating that it was sympathetically driven. These findings agree with and extend those of Brown and others (Brown et al. 1982, Grosskreutz and Brody 1988). who reported that CRHinduced tachycardia in resting rats was mediated by SNS activity as it was accompanied by an increase in catecholamine response that could be blocked by chlorisondamine, a nicotinic ganglionic blocker. However, the present data show that in atenolol treated rats, $\mathrm{CRH}$ infusion initially enhanced HR slightly as compared to saline infusion. This could be explained by a positive chronotropic effect of CRH involving activation of $\beta 2$ adrenoceptors at the SA node (Takei et al. 1992) or an effect by the CRH-induced elevation of the concentration of plasma $E$, which shows relative $\beta 2$-selectivity (Brown et al. 1983). Normally, cardiac sympathetic effects are predominantly mediated via $\beta 1$ adrenoceptors. However, Hall et al. (1991) reported that treatment with selective $\beta 1$-blockers in humans can increase cardiac responsiveness to $\beta 2$-adrenoceptor stimulation.

In the present study, the contribution of vagal activity in CRH-induced cardiac responses was determined by the use of the PQ interval. Vagal activation elongates, whereas sympathetic activation shortens the PQ interval (Levy and Zieske 1969, Croiset et al. 1994). Therefore, a CRH-induced increase in SNS activity is expected to shorten the PQ interval. There was, however, only a slight but not significant reduction in PQ interval, suggesting that $\mathrm{CRH}$ had enhanced vagal activity also. The finding that, in atenolol pre-treated rats, $\mathrm{CRH}$ infusion resulted in an increase in PQ interval confirmed this notion. Overton and colleagues (1990b) reported that icv CRH $(0.75 \mu \mathrm{g})$ induced an increase in $\mathrm{HR}$ of 90 beats/min in rats under resting conditions. After pre-treatment with a cholinergic muscarinic antagonist (atropine methylnitrate) icv CRH resulted in an increase in HR of 60 beats/min, indicating sympathetic activation. After pre-treatment with an adrenergic $\beta 1, \beta 2-b l o c k e r$ (propranolol) icv CRH induced a tachycardia of 40 beats/min, which was explained by a withdrawal of vagal activity. Fisher (1989) suggested that $\mathrm{CRH}$ could act to suppress transmission and/or neurotransmitter release at the CNS terminals of afferent baroreceptor fibers, leading to activation of sympathetic outflow and withdrawal of cardiac parasympathetic tone. In the present study, an increase rather than decrease in vagal activity was found after CRH $(2 \mu \mathrm{g})$ administration under resting conditions, resulting in a less pronounced tachycardia as compared to the above mentioned studies. Overton and co-workers (1990b) showed that surgical removal of the baroreflex sensory nerves could not prevent the $\mathrm{CRH}$-induced cardiovascular changes, indicating that it is unlikely that $\mathrm{CRH}$ acts exclusively at the CNS terminals of afferent baroreceptor fibers. Probably, the CRH system is a heterogeneous system in the brain which has divergent effects on vagal outflow: withdrawal of vagal activity via inhibition of the baroreceptor reflex nd increase of vagal activity via direct projections to vagal nuclei in the brain stem. 
The present data show that icv treatment with CP$154,526(10$ or $25 \mu \mathrm{g})$ alone did not significantly affect any of the measured parameters under resting conditions. Yet icv infusion of CP-154,526, in both doses, did inhibit the $\mathrm{CRH}$-induced $\mathrm{HR}$ and catecholamine response. The absence of effects of CP-154,526 in resting rats therefore underscores the notion that endogenous $\mathrm{CRH}$ in the brain likely does not play a role in the tonic regulation of the ANS activity under resting, low arousal conditions (Diamant and De Wied 1991). Yet, the reduction by $\mathrm{CP}-154,526$ of the $\mathrm{CRH}$-induced $\mathrm{HR}$ response indicates a role for the CRH type 1 receptor in CRH-induced cardiac activity. This reduction is likely explained by a reduction in sympathetic activity, since CP-154,526 significantly antagonized the CRH-induced increase in plasma $\mathrm{NE}$ and E levels. Although CP-154,526 treatment resulted in a reduction of the CRH-induced HR response, no significant effect on the PQ interval was found. As $\mathrm{CRH}$ treatment itself did not significantly affect the PQ interval, it is difficult to evaluate the involvement of the $\mathrm{CRH}$ type 1 receptor in $\mathrm{CRH}$-induced vagal activation.

In accordance with findings of Schulz et al. (1996). our data show that CP-154,526 treatment significantly reduced the CRH-induced increase in plasma ACTH. This confirms the effectiveness of the CP-154,526 infusion and accords with the notion that central CRH type 1 receptors are involved in the regulation of HPA-activity. It should be noted that CP-154,526 treatment did not result in a complete blockade of the CRH-induced increase in HR and plasma concentrations of NE and E. The data show that the relatively high dose $(25 \mu \mathrm{g})$ did not lead to a further reduction of the cardiac and catecholamine response as compared to the lower dose $(10 \mu \mathrm{g})$, indicating the absence of a dose-dependent relationship. It is therefore likely that another receptor, such as the CRH type 2 receptor, is also involved in $\mathrm{CRH}$-induced autonomic changes.

The present data further show that $\mathrm{CRH}$ increased GA and that this effect followed the tachycardiac response: HR started to increase during or just after infusion, whereas the CRH-induced increase in GA started between $\mathrm{t}=20$ and $35 \mathrm{~min}$. Furthermore, our data show that CP-154,426 treatment resulted in a reduction of the CRHinduced GA response, which followed the attenuation in $\mathrm{HR}$ response induced by $\mathrm{CP}-154,526$. This indicates that the HR response was not a consequence of increased locomotor activity, but was a direct effect of icv $\mathrm{CRH}$. CP154,526 treatment resulted in a $50 \%$ reduction of both the $\mathrm{CRH}$-induced HR and GA response. It may well be that the increase in GA was a secondary effect of the CRHinduced increase in HR. Thus, it is possible that CP-154,526 treatment leads to an attenuation of locomotor behavior due to an indirect result of the reduction in tachycardia, rather than a direct effect of CRH type 1 blockade.

In summary, the present study demonstrates that exogenous CRH activates the SNS and PSNS. Further- more, the data provide evidence that the CRH type 1 receptor is involved in these responses.

\section{ACKNOWLEDGMENTS}

The authors thank M.H. Broekhoven, M. Agterberg, J.C. Frankhuijzen and H.A. Spierenburg for their skilled technical assistance.

This research is supported by a research grant from the Netherlands Heart Foundation.

R. Stam was supported by the Janssen Research Foundation.

\section{REFERENCES}

Brown MJ, Brown DC, Murphy MB (1983): Hypokalemia from beta2-receptor stimulation by circulating epinephrine. N Engl J Med 309(23):1414-1419

Brown MR, Fisher LA, Spiess J, Rivier C, Rivier J, Vale WW (1982): Corticotropin-releasing factor: actions on the sympathetic nervous system and metabolism. Endocrinology 111:928-931

Brown MR, Fisher LA (1985): Corticotropin-releasing factor: effects on the autonomic nervous system and visceral systems. Federation Proc 44:243-248

Chalmers DT, Lovenberg TW, De Souza EB (1995): Localization of novel corticotropin-releasing factor receptor (CRF2) mRNA expression to specific subcortical nuclei in rat brain: comparison with CRF1 receptor mRNA expression. J Neurosci 15(10):6340-6350

Croiset G, Raats CJI, Nijsen MJMA, Wiegant VM (1994): Differential effects of cholinergic and adrenergic agents on $\mathrm{P}-\mathrm{R}$ and R-R intervals in rat ECG. Neurosci Res Commun 14:75-84

Diamant M, De Wied D (1991): Autonomic and behavioral effects of centrally administered corticotropin-releasing factor in rats. Endocrinology 129:446-454

Dieterich KD, Lehnert H, De Souza EB (1997): Corticotropinreleasing factor receptors: an overview. Exp Clin Endocrinol Diabetes 105(2):65-82

Fisher LA, Jessen G, Brown MR (1983): Corticotropin-releasing factor (CRF): mechanism to elevate mean arterial pressure and heart rate. Regul Pept 5:153-161

Fisher LA (1989): Central autonomic modulation of cardiac baroreflex by corticotropin-releasing factor. Am J Physiol 256:H949-H955

Grigoriadis DE, Lovenberg TW, Chalmers DT, Liaw C, De Souza EB (1996): Characterization of corticotropin-releasing factor receptor subtypes. In: Crawley JN, McLean S, editors. Annals of the New York Academy of Sciences; Neuropeptides: basic and clinical advances. 780th. New York:New York Academy of Sciences. pp 60-80. 
Grosskreutz CL, Brody MJ (1988): Regional hemodynamic responses to central administration of corticotropinreleasing factor (CRF). Brain Res 442:363-367

Hall JA, Petch MC, Brown MJ (1991): In vivo demonstration of cardiac beta 2-adrenoreceptor sensitization by beta 1-antagonist treatment. Circ Res 69(4):959-964

Heinrichs SC, Lapsansky J, Lovenberg TW, De Souza EB, Chalmers DT (1997): Corticotropin-releasing factor CRF1, but not CRF2, receptors mediate anxiogenic-like behavior. Regul Pept 71(1):15-21

Korte SM, Bouws GAH, Bohus B (1993): Central actions of corticotropin-releasing hormone $(\mathrm{CRH})$ on behavioral, neuroendocrine, and cardiovascular regulation: brain corticoid receptor involvement. Hormones and Behavior 27:167-183

Lake CR, Ziegler MG, Kopin IJ (1976): Use of plasma norepinephrine for evaluation of sympathetic neuronal function in man. Life Sciences 18:1315-1325

Levy MN, Zieske H (1969): Autonomic control of cardiac pacemaker activity and atrioventricular transmission. J Appl Physiol 27:465-470

Nijsen MJMA, Croiset G, Diamant M, Broekhoven MH, De Wied D, Wiegant VM (1998a): Vagal activation in novelty-induced tachycardia during the light phase in the rat. Physiol Behav 63(2):233-239

Nijsen MJMA, Croiset G, Diamant M, Stam R, Delsing D, De Wied D, Wiegant VM (1998b): Conditioned fearinduced tachycardia in the rat; vagal involvement. Eur J Pharmacol 350:211-222

Overton JM, Davis-Gorman G, Fisher LA (1990a): Central nervous effects of CRF and angiotensin II on cardiac output in conscious rats. J Appl Physiol 69:788-791

Overton JM, Davis-Gorman G, Fisher LA (1990b): Central nervous system cardiovascular actions of CRF in sinoaorticdenervated rats. Am J Physiol 258:R596-R601
Primus RJ, Yevich E, Baltazar C, Gallager DW (1997): Autoradiographic localization of CRF1 and CRF2 binding sites in adult rat brain. Neuropsychopharmacology 17(5):308-316

Schulz DW, Mansbach RS, Sprouse J, Braselton JP, Collins J, Corman M, Dunaiskis A, Faraci S, Schmidt AW, Seeger T, Tingley FD, Winston E, Chen YL, Heym J (1996): CP154,526 , a potent and selective nonpeptide antagonist of corticotropin releasing factor receptors. Proc Natl Acad Sci U S A 93:10477-10482.

Smith GW, Aubry JM, Dellu F, Contarino A, Bilezikjian LM, Gold LH, Chen R, Marchuk Y, Hauser C, Bentley CA, Sawchenko PE, Koob GF, Vale W, Lee KF (1998): Corticotropin releasing factor receptor 1-deficient mice display decreased anxiety, impaired stress response, and aberrant neuroendocrine development. Neuron 20(6): 1093-1102

Steffens AB (1969): A method for frequent sampling of blood and continuous infusion of fluids in the rat without disturbing the animal. Physiol Behav 4:833-836

Takei M, Furukawa Y, Narita M, Murakami M, Ren LM, Karasawa Y, Chiba S (1992): Sympathetic stimulation activates both beta 1- and beta 2-adrenoceptors of SA and AV nodes in anesthetized dog hearts. Jpn J Pharmacol 59(1):23-30

Timpl P, Spanagel R, Sillaber I, Kresse A, Reul JM, Stalla GK, Blanquet V, Steckler T, Holsboer F, Wurst W (1998): Impaired stress response and reduced anxiety in mice lacking a functional corticotropin-releasing hormone receptor. Nat Genet 19(2):162-166

Van Oers JWAM, Tilders FJH (1991): Non-adrenocorticotropin mediated effects of endogenous corticotropinreleasing factor on the adrenocortical activity in the rat. J Neuroendocrinol 3:119-121 